\title{
RAMI Evaluation of the Beam Source for the DEMO Neutral Beam Injectors
}

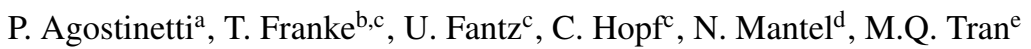 \\ ${ }^{a}$ Consorzio RFX (CNR, ENEA, INFN, Università di Padova, Acciaierie Venete SpA) Corso Stati Uniti 4 - 35127 Padova (Italy) \\ ${ }^{b}$ EUROfusion Consortium, Boltzmannstr. 2, 85748 Garching, Germany \\ ${ }^{c}$ Max-Planck-Institut für Plasmaphysik, Boltzmannstr. 2, 85748 Garching, Germany \\ ${ }^{d}$ Culham Centre for Fusion Energy, Science Centre, Abingdon, Oxon, OX14 3DB, UK \\ ${ }^{e}$ Ecole Polytechnique Federale de Lausanne (EPFL), Swiss Plasma Center (SPC), CH-1015 Lausanne, Switzerland
}

\begin{abstract}
DEMO is a first-of-a-kind DEMOnstration fusion power plant [1, 2] and is intended to follow the ITER experimental reactor. The main goal of DEMO will be to demonstrate the possibility to produce electric energy for the grid from the fusion reaction early in the second half of the century. The injection of high energy neutral $(1 \mathrm{MeV})$ particle beams is one of the main tools to heat the plasma up to fusion conditions, control the plasma burn phase and ramp the plasma down. Within the EUROfusion Framework a conceptual design of the Neutral Beam Injector (NBI) for the DEMO fusion reactor is currently being developed. Thereby, Reliability, Availability, Maintainability and Inspectability (RAMI) have to be taken into consideration for the conceptual design of the DEMO NBI, together with the exploitation of the currently available return of experience from the ITER NBIs. Comparing the failure risk of two different source concepts due to the considered failure modes has allowed for further design developments aiming at exploiting the advantages of the modular approach while minimizing its drawbacks.
\end{abstract}

Keywords: RAMI, evaluation, beam source, negative ions

\section{Introduction}

DEMO (DEMOnstration fusion power plant) is a proposed nuclear fusion power plant that is intended to follow the ITER experimental reactor. While in ITER the goal is to demonstrate the possibility to obtain a plasma able to sustain the fusion nuclear reaction, in the European DEMO the main objective is to prove the industrial feasibility of fusion by showing the electricity production from the fusion reaction, the safety aspects and the Tritium self sufficiency. The injection of high energy beams of deuterium neutrals $\left(\mathrm{D}^{0}\right)$ is one of the main tools to heat the plasma up to fusion conditions and to contribute to the plasma rotation and to the required current drive, by adopting a tangential co-injection layout of the beamlines. In the framework of the EUROfusion work package on heating and current drive (WPHCD) within the Power Plant Physics and Technology (PPPT) activities, a conceptual design of the Neutral Beam Injectors (NBIs) for the DEMO fusion reactor has been developed by Consorzio RFX and IPP in collaboration with other European research institutes and integrated into the European DEMO reference design.

The current functional requirement for the NBI system of DEMO1 is to provide $50 \mathrm{MW}$ of core plasma heating by means of deuterium neutrals $\left(\mathrm{D}^{0}\right)$ with minimum shine-through [2]. Other fundamental choices driving the design, agreed in the first years of development [3], are an average divergence of the beamlets lower or equal than $7 \mathrm{mrad}$, a target beam-on time of $7200 \mathrm{~s}$, a co-extracted electron fraction $\left(\mathrm{e}^{-} / \mathrm{D}^{-}\right)$lower than 1 and a number of beamlines equal to 3 . The design of DEMO NBI is under development considering the choices above as requirements and taking into account the return of experience from the existing negative ion-based neutral beam injectors (JT60 NBIs, LHD NBIs), the existing test facilities on negative ions for fusion (ELISE, BATMAN, SPIDER, MTF and NITS teststands at QST, RNIS teststand at NIFS), and from the neutral beam injectors under design or construction (MITICA, ITER DNB, ITER HNB).

\section{Description of the RAMI analysis}

During the development of the DEMO NBI design, a highly modular design with a large number of sub-sources (i.e. 20 subsources) has been proposed for the beam source [4]. In fact, this approach was meant to bring some advantages:

- A better alignment between the corresponding apertures of the grids, also in presence of thermal expansion, resulting in a better overall optics of the neutral beam. This is due to the fact that the modules have a significantly smaller size than the whole accelerator, hence the horizontal and vertical deformations are also reduced compared to a less modular solution.

- The R\&D phase can be carried out using a small beam source, which is more flexible and less expensive than a full size prototype. Once optimized, the sub-source can be replicated to form a cluster in the DEMO NBI.

On the other hand, there are also some drawbacks, like a more complex construction of the ion sources and of the extraction/acceleration system, that could bring to reliability and availability issues. 
(a)

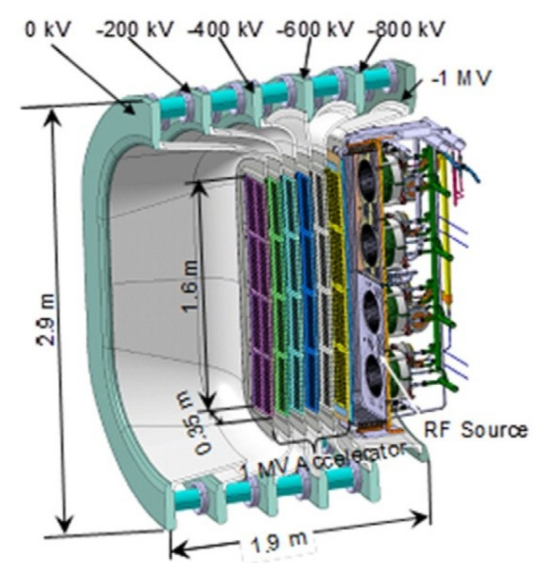

(b)

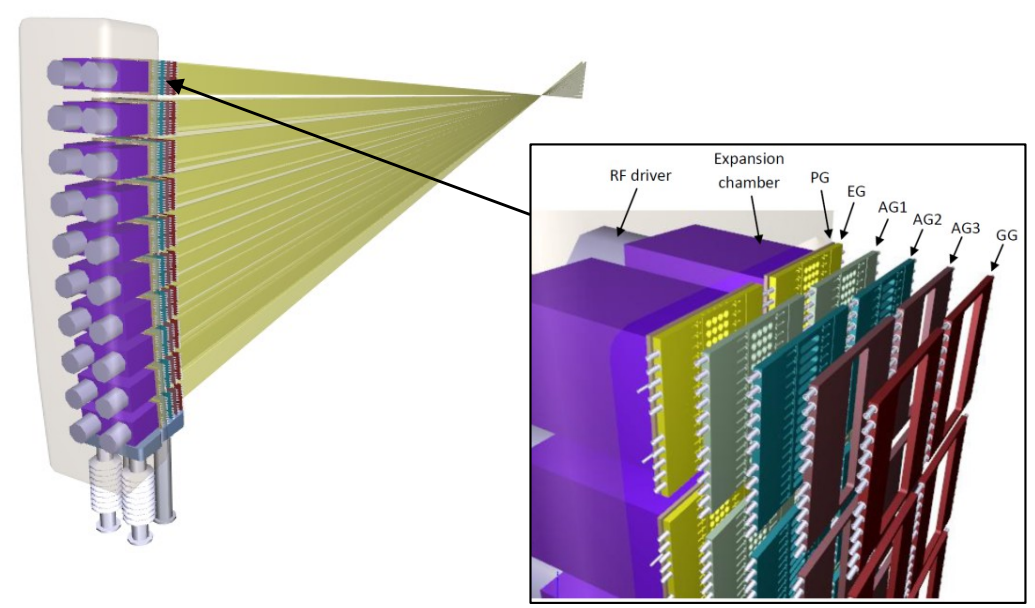

Figure 1: Views of the two considered design concepts: (a) MITICA beam source; (b) DEMO 2016 NBI. PG: Plasma Grid; EG: Extraction Grid; AG: Acceleration Grids; GG: Grounded Grid.

In order to evaluate in a systematic way the advantages and disadvantages of a highly modular design of the DEMO NBI beam source, following a recommendation made during a design progress meeting of the EUROfusion WPHCD, a comparative RAMI evaluation has been carried out. Namely, two options were considered for the beam source of the DEMO NBI:

1. A low modularity beam source (LMBS) featuring a single expansion chamber, 8 RF drivers, 3 cesium ovens and 4 segments per grid. This is the beam source adopted in MITICA and ITER NBI, shown in Fig. 1a and described in [5].

2. A high modularity beam source (HMBS) featuring 20 beam sources, each with its RF driver and cesium oven, and 20 segments per grid. This is the beam source proposed in 2016 for DEMO NBI, shown in Fig. 1b and described in [3].

The first step of each RAMI Analysis is to identify the main failure modes of each primary function. To do this, the main sources of information were:

- The FMEA (Failure Mode and Effects Analysis) of the ITER NBI carried out by the RFX team in 2009 [6].

- The RAMI Analysis of NBI H\&CD System made by ITER-KOREA DA (\& KAERI) in 2009 [7].

- The FMECA (Failure Mode, Effects, and Criticality Analysis) of the HNB Beam Source made by ITER in 2014 [8].

- The experience gained by the first author during the experimental campaigns to which he participated in the main existing experiments on the field (ELISE, MANITU and BATMAN ion sources at IPP Garching, NBI teststand at NIFS, MTF and NITS teststands at QST).

At the end of this process, 28 failure modes were identified, split in the various systems.

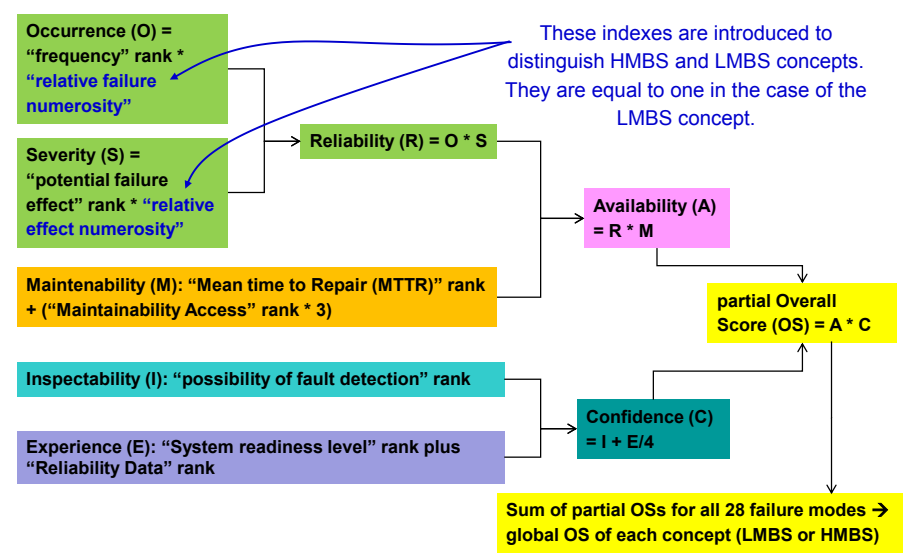

Figure 2: Scheme of the RAMI score evaluation for the beam source. Reliability is estimated as a combination of the Occurrence and Severity, Availability as a combination of Reliability and Maintainability, Confidence as a combination of Inspectability and Experience, and the Overall Score (OS) as a combination of Availability and Confidence. The global OS of both conceptual designs (LMBS and HMBS) is then calculated summing the OS of each of the 28 failure modes. 
Table 1: Primary functions of the beam source and related components. For each primary function, a failure mechanism is reported as an example, with the related evaluations on the rankings chosen on the basis of the available data.

\begin{tabular}{|c|c|c|c|c|c|c|c|c|c|c|c|c|}
\hline $\begin{array}{l}\text { Primary function / } \\
\text { Component }\end{array}$ & $\begin{array}{c}\text { Number } \\
\text { of failure } \\
\text { modes }\end{array}$ & $\begin{array}{l}\text { Example of a failure } \\
\text { mode }\end{array}$ & $\begin{array}{l}\text { Potential } \\
\text { failure } \\
\text { frequency }\end{array}$ & $\begin{array}{c}\text { Relative } \\
\text { failure } \\
\text { numero } \\
\text { sity }\end{array}$ & $\begin{array}{l}\text { Potential } \\
\text { failure } \\
\text { effect }\end{array}$ & $\begin{array}{c}\text { Relativ } \\
\text { e effect } \\
\text { numero } \\
\text { sity }\end{array}$ & $\begin{array}{l}\text { Mean time to } \\
\text { Repair (MTTR) }\end{array}$ & $\begin{array}{c}\text { Maintainan } \\
\text { ce access } \\
\text { requires }\end{array}$ & $\begin{array}{l}\text { Potential } \\
\text { Detection } \\
\text { Methode }\end{array}$ & $\begin{array}{c}\text { Possibility of } \\
\text { fault } \\
\text { detection }\end{array}$ & System readiness level & Reliability Data \\
\hline $\begin{array}{l}\text { Producing negative } \\
\text { ions / lon source }\end{array}$ & 12 & $\begin{array}{c}\text { Fault on Cs ovens - } \\
\text { heating wire broken } \\
\rightarrow \text { Too low production } \\
\text { of negative ions }\end{array}$ & $\begin{array}{l}\text { 4. High } \\
\rightarrow 2 Y<M T T F \\
\quad<20 Y\end{array}$ & 6.7 & $\begin{array}{l}\text { 2. Reduced } \\
\text { plant output }\end{array}$ & 0.3 & $\begin{array}{c}3 . \\
\begin{array}{c}\text { 1day<MTTR }<1 \\
\text { week }\end{array}\end{array}$ & $\begin{array}{l}\text { 4. Breach of } \\
\text { Vacuum }\end{array}$ & $\begin{array}{l}\text { Caesium oven } \\
\text { temperature; } \\
\text { spectroscopy }\end{array}$ & $\begin{array}{l}\text { 1. Continuous } \\
\text { monitoring }\end{array}$ & $\begin{array}{l}\text { 3. Component and/or } \\
\text { breadboard critical function } \\
\text { verification in relevant } \\
\text { environment }\end{array}$ & $\begin{array}{l}\text { 3. Data based on } \\
\text { similar system in } \\
\text { similar environment }\end{array}$ \\
\hline $\begin{array}{l}\text { Extraction of } \\
\text { negative ions / } \\
\text { Extraction Grid }\end{array}$ & 5 & $\begin{array}{l}\text { Fault on the dissimilar } \\
\text { joint } \mathrm{Cu} \text {-SS of the } \\
\text { extractor } \\
\rightarrow \text { Water leak }\end{array}$ & $\begin{array}{c}3 . \\
\text { Moderate } \\
\rightarrow 20 \mathrm{Y}<\mathrm{MT} \\
\mathrm{TF}<200 \mathrm{Y}\end{array}$ & 1.5 & $\begin{array}{l}\text { 3. No NBI } \\
\text { output } \\
\text { controlled } \\
\text { shut down }\end{array}$ & 1 & $\begin{array}{c}5 . \\
\text { 2months }<\mathrm{MTT} \\
\text { R<1 year }\end{array}$ & $\begin{array}{l}\text { 4. Breach of } \\
\text { Vacuum }\end{array}$ & $\begin{array}{l}\text { Spectroscopy, } \\
\text { camera }\end{array}$ & $\begin{array}{l}\text { 2. Detection } \\
\text { when failure } \\
\text { occur }\end{array}$ & $\begin{array}{l}\text { 2. Mock-up demonstrating the } \\
\text { critical functions of the } \\
\text { element in a relevant } \\
\text { environment }\end{array}$ & $\begin{array}{l}\text { 3. Data based on } \\
\text { similar system in } \\
\text { similar environment }\end{array}$ \\
\hline $\begin{array}{l}\text { Acceleration and } \\
\text { focusing of } \\
\text { negative ions / } \\
\text { Acceleration grids }\end{array}$ & 6 & $\begin{array}{l}\text { Misalignment on } \\
\text { accelerator grids --> } \\
\text { incorrect } \\
\text { acceleration/focusing }\end{array}$ & $\begin{array}{l}\text { 2. Low } \\
\rightarrow 200 \mathrm{Y}<\mathrm{M} \\
\mathrm{TTF}<2000 \mathrm{Y}\end{array}$ & 5 & $\begin{array}{l}\text { 2. Reduced } \\
\text { NBI output }\end{array}$ & 0.2 & $\begin{array}{c}5 . \\
2 \text { months }<\mathrm{MTT} \\
\mathrm{R}<1 \text { year }\end{array}$ & $\begin{array}{l}\text { 4. Breach of } \\
\text { Vacuum }\end{array}$ & $\begin{array}{c}\text { Temperature } \\
\text { measurement } \\
\mathrm{s}\end{array}$ & $\begin{array}{l}\text { 2. Detection } \\
\text { when failure } \\
\text { occur }\end{array}$ & $\begin{array}{l}\text { 1. Mock-up demonstrating the } \\
\text { element performance for the } \\
\text { operational environment }\end{array}$ & $\begin{array}{l}\text { 2. Data based on same } \\
\text { system in different } \\
\text { operating } \\
\text { environment }\end{array}$ \\
\hline $\begin{array}{l}\text { Providing HV } \\
\text { electrical } \\
\text { insulation / } \\
\text { Insulators }\end{array}$ & 2 & $\begin{array}{l}\text { Failure of BS insulators } \\
\rightarrow \text { Insulation loss }\end{array}$ & $\begin{array}{l}\text { 1. Very } \\
\text { Low } \rightarrow \\
\text { MTTF }>200 \\
\text { OY }\end{array}$ & 1 & $\begin{array}{l}\text { 3. No NBI } \\
\text { output } \\
\text { controlled } \\
\text { shut down }\end{array}$ & 1 & $\begin{array}{c}4 . \\
\text { 1week }<\text { MTTR< } \\
\text { 2months }\end{array}$ & $\begin{array}{l}\text { 4. Breach of } \\
\text { Vacuum }\end{array}$ & $\begin{array}{c}\text { Visual } \\
\text { inspection }\end{array}$ & $\begin{array}{l}\text { 4. Detection } \\
\text { during Short } \\
\text { Term } \\
\text { Maintenance }\end{array}$ & $\begin{array}{l}\text { 5. Analytical and experimental } \\
\text { critical function and/or } \\
\text { characteristic proof-of- } \\
\text { concept }\end{array}$ & $\begin{array}{l}\text { 4. Data based on } \\
\text { similar system in } \\
\text { different operating } \\
\text { environment }\end{array}$ \\
\hline $\begin{array}{l}\text { Deflection \& dump } \\
\text { of electrons / } \\
\text { Extractor and } \\
\text { accelerator }\end{array}$ & 3 & $\begin{array}{l}\text { Fault of most } \\
\text { acceleration grid } \\
\text { permanent magnets } \\
\rightarrow \text { No electron } \\
\text { deflection }\end{array}$ & $\begin{array}{l}\text { 1. Very } \\
\text { Low } \rightarrow \\
\text { MTTF }>200 \\
\text { OY }\end{array}$ & 1 & $\begin{array}{l}\text { 2. Reduced } \\
\text { NBI output }\end{array}$ & 1 & $\begin{array}{c}5 . \\
\text { 2months }<\mathrm{MTT} \\
\text { R }<1 \text { year }\end{array}$ & $\begin{array}{l}\text { 4. Breach of } \\
\text { Vacuum }\end{array}$ & $\begin{array}{l}\text { Check with } \\
\text { gaussmeter }\end{array}$ & $\begin{array}{l}\text { 5. Detection } \\
\text { during Long } \\
\text { Term } \\
\text { Maintenance }\end{array}$ & $\begin{array}{l}\text { 2. Mock-up demonstrating the } \\
\text { critical functions of the } \\
\text { element in a relevant } \\
\text { environment }\end{array}$ & $\begin{array}{l}\text { 1. Data based on same } \\
\text { system in same } \\
\text { operating } \\
\text { environment }\end{array}$ \\
\hline
\end{tabular}

Each failure mode was then evaluated according to the procedure suggested by CCFE [9]. Namely, the indexes in Fig. 2 were evaluated with rankings having increased criticality, hence a higher score means a higher criticality. An example of a failure mode for each primary function is reported in Tab. 1.

The RAMI compliance of each conceptual design (LMBS and HMBS) were evaluated asking the opinion of NBI experts regarding a set of primary indexes for each failure mode: Occurrence (how often a failure happens), Severity (how damaging it is), Maintainability (how much time it is needed to repair the damage), Inspectability (how detectable the damage is) and Experience (how much we know about that failure mode). After the discussion, the agreed rankings for each index were inserted in an excel table similar to the one of Tab. 1 but including all the 28 considered failure modes. Then, a set of linear calculations were carried out to evaluate the composite quantities (Reliability, Availability and Confidence), as shown in the scheme of Fig. 2. At the end of the process, for each of the two considered conceptual designs we obtained a partial Overall Score (OS) for each failure mode and then a global OS by summing all the partial OSs of that conceptual design (LMBS or HMBS). The two global OS can then be compared in order to evaluate which design is more RAMI compliant according to this procedure.

Two factors were introduced to take into account the difference between the LWBS and the HMBS:

- the relative failure numerosity: how much the failure mode is more likely to happen in the HMBS compared with the LMBS. As a first approximation this is calculated as the number of identical components (for example, cesium ovens) in the HMBS divided by the number of identical components in the LMBS. This index affects the Occurrance rank of the HMBS case, as shown in Fig. 2.

- the relative effect numerosity: how much larger is the de- crease of performance due to a certain failure mode in the LMBS compared to the HMBS. As a first approximation, this is calculated as the damage to the NBI performance occurring if one component fails in the HMBS beam source divided by the damage to the NBI performance occurring if one component fails in the LMBS. This index affects the Severity rank of the HMBS case, as shown in Fig. 2.

No factors were introduced in the maintainability and inspectability indexes to differentiate the two concepts, because as a first approximation, due to lack of knowledge, these aspects are assumed to be equal in the two cases.

The main conclusions of the RAMI evaluation are summarized here below:

- Considering all the 28 considered failure modes, the global OS of the LMBS is $20 \%$ lower than the HMBS one. This means that the LMBS is about $20 \%$ more "RAMI compliant" than the HMBS. However, the extremely low amount of statistic data implies that this result is affected by uncertainties that could be higher than the $20 \%$ difference. An effort to estimate this uncertainty will be made in the next future.

- For some failure modes, like the ones related to the cesium ovens and the water leaks, the HMBS approach brings a larger number of components and hence a higher score (i.e. more criticality). These are partially (but not totally) compensated by the fact that the foreseen damage to the beam source performance is reduced following the HMBS approach compared to the LMBS approach.

\section{Updated design of the DEMO NBI}

As a consequence of the RAMI analysis, the conceptual design of the DEMO NBI was modified in several parts. In par- 
ticular, the updated design exploits more the return of experience from the ITER HNB, and in particular from the MITICA experiment that is currently under construction. The main characteristics of the 2019 design of the DEMO NBI, shown in Fig. 3, compared to the ITER HNB are:

- The same number (1280) and size of apertures on the grids.

- The same number of grids (7) separated by an extraction gap of about $10 \mathrm{kV}$ (distance between the grids of $6 \mathrm{~mm}$ ) and 5 acceleration gaps of $200 \mathrm{kV}$ each (distance between the grids of $105 \mathrm{~mm}$ ).

- The same layout and size of the beamlet groups.

- A similar design of the accelerator support frames (bathtub shape) and related insulators.

- No tilting mechanisms but instead the beam source is rigidly connected to the beam source vessel. In fact, the tilting of the beam source implies significant complications to the design and is not required for DEMO.

- A gas neutralizer (ITER-like design) having 4 vertical slits, with beam driven plasma neutralizer [10] as an alternative option if the on-going studies will prove the concept.

- Each grid composed by 8 segments with dimensions of about $0.5 \mathrm{~m} \times 0.5 \mathrm{~m}$, fixed to a stainless steel frame, to obtain a better alignment and an easier manufacturing of the copper parts. Each segment has 1 bend, cooling from sides and reference position for thermal expansion in the middle of the grid.

- 4 racetrack RF drivers [11].

- 2 ion source modules having dimensions of about $1 \mathrm{~m} \times 1$ $\mathrm{m}$.

- An ITER-like transmission line, insulated in $\mathrm{SF}_{6}$.

- ITER-like fast shutter and absolute valve at the exit of the beamline.

The motivations to choose a $1 \mathrm{MeV}$ energy of the particles, instead of $800 \mathrm{keV}$ as in the previous version [4], were that:

- The negative impact on the availability of higher energy beam source could be reduced by the use of the return of experience from ITER.

- More energy means more power with the same current, and beam current is limited by size of the ion source and physics of the negative ion extraction, as large amounts of electrons are also extracted.

The motivations to choose a design with four short beam blades, instead of two long beam blades as in the DEMO 2016 design [4], were that:
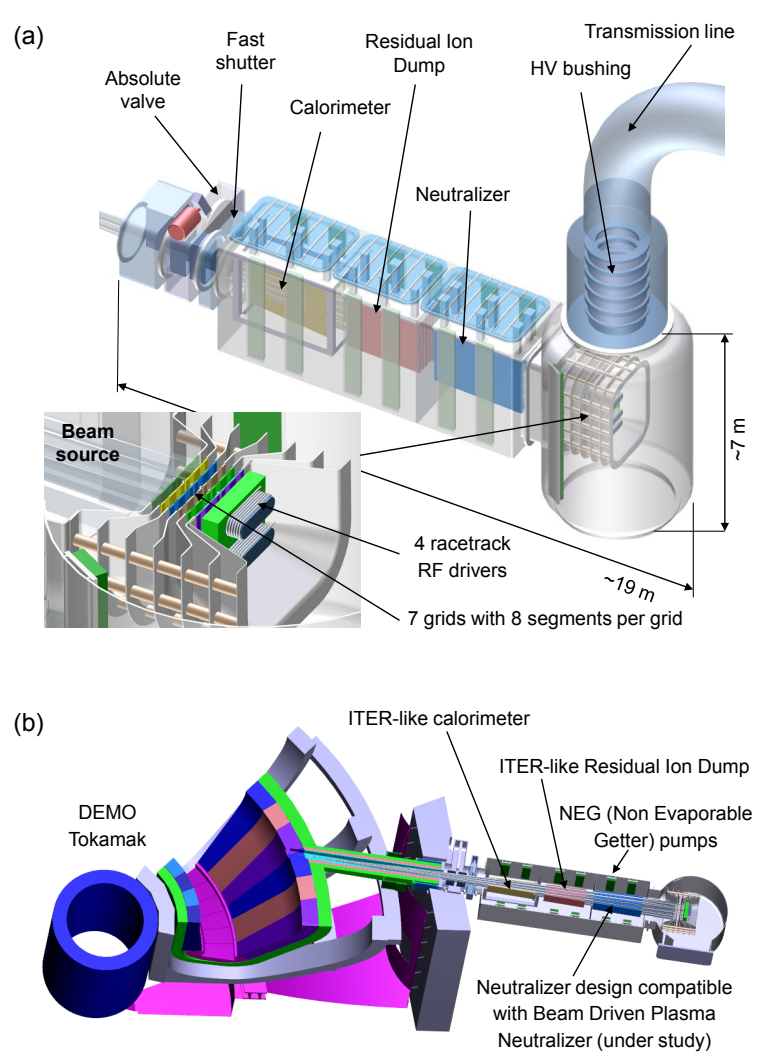

Figure 3: DEMO NBI 2019 conceptual design: (a) overall view with focus on the beam source; (b) integration into the DEMO baseline design. 
- A more compact in height (or square-like) shape is more suitable both for a gas or a plasma neutralizer. In fact, for gas neutralizers the density distribution is more uniform with a compact shape, and for plasma neutralizers there are less plasma losses as the surface-to-volume ratio is smaller, as shown in [12].

- The fast shutter and absolute valve adopted for ITER NBI can be used also for DEMO NBI. This is particularly useful for the all-metal absolute valve, whose development has required large $\mathrm{R} \& \mathrm{D}$ and industrial efforts for the ITER HNB dimensions (1.6 $\mathrm{m}$ bore diameter) which is at the edge of the current state-of-the-art, as we understood after a survey in the industry. A thin-and-tall design of the NBI would have required a new and complex R\&D phase to develop a new all-metal valve with a bore diameter about double (around $3 \mathrm{~m}$ ).

- The main reason to adopt a two blades layout instead of a four blades one was the presence of the photo-neutralizer [3], that was abandoned from the DEMO baseline design due to its lack of maturity but will be further investigated under prospective $R \& D$ in view to a future power plant after DEMO.

\section{Conclusions}

A comparative RAMI evaluation has been carried out to compare the high modularity beam source developed for the DEMO NBI in 2016 with the low modularity beam source developed for the MITICA experiment and the ITER HNB. The analysis was carried out following the expertise of CCFE system engineering team on the subject and the expert opinions in the field of NBI. The main result is that a high modularity design like the one proposed in 2016 for the DEMO NBI is found to be less RAMI compliant than a low modularity one as the present design of the MITICA beam source. As a consequence, the design of the DEMO NBI was revised following the output of several meetings and design evaluations, in order to take into account the indications from the RAMI analysis, the status of the $R \& D$ activities going on in the European laboratories and the return of experience from ITER. In particular, the DEMO NBI design is now closer to the MITICA (or ITER HNB) one. In fact, the modularity has been reduced passing from 20 to 2 ion source modules (it is 1 in ITER HNB), while the beam shape has been changed to a four-blades one (as in MITICA and ITER HNB), rather than a two-blades one. Possible improvements could come from the adoption of a beam driven plasma neutralizer instead of a gas neutralizer or energy recovery systems, that could increase the efficiency. Evaluations are on-going also regarding other key aspects, like the remote maintenance and the vacuum pumping systems.

\section{Acknowledgements}

This work has been carried out within the framework of the EUROfusion Consortium and has received funding from the Euratom research and training programme 2014-2018 and 2019-2020 under grant agreement No 633053. The views and opinions expressed herein do not necessarily reflect those of the European Commission.

\section{References}

[1] T. Donné, Scientific and technical challenges on the road towards fusion electricity, Journal of Instrum. 2017, Vol. 12, https://doi.org/10.1088/1748-0221/12/10/C10008.

[2] G. Federici, et. al., Overview of the design approach and prioritization of R\&D activities towards an EU DEMO, Fusion Eng. Des. 109-111 (2016) 1674.

[3] P. Sonato et al., Conceptual design of the DEMO neutral beam injectors: main developments and R\&D achievements, Nucl. Fusion, vol. 57 (2017) 056026.

[4] P. Sonato, et al., Conceptual design of the beam source for the DEMO Neutral Beam Injectors, New J. Phys. 18 (2016) 125002.

[5] D. Marcuzzi, et al., Final design of the beam source for the MITICA injector, Rev. Sci. Instrum. 87, 02B309 (2016).

[6] N. Pomaro, at al., Potential failure mode and effects analysis for the ITER NB injector, Fusion Eng. Des. 84 (2009) 466.

[7] Doo-Hee Chang, et al., RAMI Analysis of NBI H\&CD System, ITER document ITER_D_2N3SS9 v5.1, 2009.

[8] D. Shah, Component failure analysis report for HNB beam source, ITER document DFZGDA v2.0, 2014.

[9] N. Mantel, EFDA_D_2N2C7A v1.1 - HCD-2.06-T002-D001 Final Report on functional attribution for RAMI on HCD, https://idm.eurofusion.org/?uid=2N2C7A.

[10] E. Surrey and A. Holmes, The beam driven plasma neutralizer, AIP Conf. Proc. 1515 (2013) 532.

[11] U. Fantz et al., Technology developments for a beam source of an NNBI system for DEMO, Fusion Eng. Des. 136 (2018) 340.

[12] C. Hopf, et al., A conceptual system design study for an NBI beamline for the European DEMO, Fusion Eng. Des. 146 (2019) 705. 